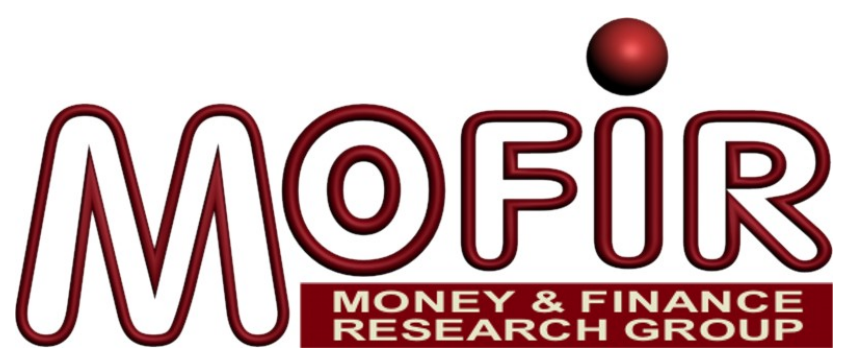

\title{
Mutual Loan-Guarantee Societies in Monopolistic Credit Markets with Adverse Selection
}

\author{
Giovanni Busetta \\ Università di Messina, \\ Department of Economics, Statistics, Mathemetics and Sociology
}

Alberto ZazZaro

Università Politecnica delle Marche, Department of Economics

$M o F_{I} R$

CFEPSR

MoFiR working paper $\mathrm{n}^{\circ} 33$

November 2009 


\title{
Mutual Loan-Guarantee Societies in Monopolistic
}

\author{
Credit Markets with Adverse Selection *
}

\author{
Giovanni Busetta $^{\dagger} \quad$ Alberto Zazzaro $^{\ddagger}$
}

June 1, 2009

\begin{abstract}
In many countries, Mutual Loan-Guarantee Societies (MLGSs) are assuming ever-increasing importance for small business lending. In this paper we provide a theory to rationalise the raison d'être of MLGSs. The basic intuition is that the foundation for MLGSs lies in the inefficiencies created by adverse selection, when borrowers do not have enough collateralisable wealth to satisfy collateral requirements and induce self-selecting contracts. In this setting, we view MLGSs as a wealth-pooling mechanism that allows otherwise inefficiently rationed borrowers to obtain credit. We focus on the case of large, complex urban economies where potential entrepreneurs are numerous and possess no more information about each other than do banks. Despite our extreme assumption on information availability, we show that MLGSs can be characterized by assortative matching in which only safe borrowers have an incentive to join the mutual society.
\end{abstract}

JEL Classification: D82, G21

Key words: Mutual Loan Guarantee Society; Group formation; Small business lending; Collateral.

${ }^{*}$ A preliminary version of this paper has been discussed at the CEIS conference on "'Banking and Finance"" (Rome). We wish to thank Piero Alessandrini, Michele Fratianni, Alberto Pozzolo and Davide Ticchi for comments. Usual disclaimer applies.

${ }^{\dagger}$ Department of Economics, Statistics, Mathematics and Sociology V. Pareto, Università di Messina, e-mail: gbusetta@unime.it.

${ }^{\ddagger}$ Department of Economics, Università Politecnica delle Marche, Money and Finance Research Group (MoFiR) and CFESPR, e-mail: a.zazzaro@univpm.it 


\section{Introduction}

In the words of the (European Commission, 2005, p. 10), Mutual Loan-Guarantee Societies (from now on MLGSs) are "collective initiatives of a number of independent businesses or their representative organisations. They commit to granting a collective guarantee to credits issued to their members, who in turn take part directly or indirectly in the formation of the equity and the management of the scheme".

As other typologies of public and private partial guarantee schemes around the World $^{1}$, MLGSs are assuming ever greater importance in small business lending. For example, according to the AECM (2005), in 2003 their member systems, represented by 29 federations of MLGSs operating in $15 \mathrm{EU}$ countries, granted guarantees for 15 billion euros to more than 2 million small firms. Moreover, the importance of MLGSs is destined to further increase in the light of Basel II Accords which state that the guarantees of such institutions could, if granted in compliance with some requirements, allow banks to mitigate credit risk associated with small business lending and to save regulatory capital.

Surprisingly, in spite of their real-world diffusion and the attention paid to MLGs in the policy arena, there has been no previous attempt to model the incentives behind their formation. In the present paper we provide a theory to rationalise the existence of an MLGS based on the contractual features of MLGS lending. While MLGSs play other important roles like screening and monitoring their associates and conducting collective bargaining with banks, our theory focuses on their distinctive function that is

\footnotetext{
${ }^{1}$ See, Beck et al. (2008), Honohan (2008) and Gonzàles et al. (2006)
} 
of providing collateral to associates. Its major contribution is to show that, abstracting from any alleged informational advantage of entrepreneurs about each other, an MLGS acts as a wealth-pooling mechanism that makes it feasible to offer separating contracts and reduces the likelihood of credit rationing.

Our analysis is related to the literature on peer group formation with adverse selection (Ghatak, 2000; Armendariz de Aghion and Gollier, 2000; Ghatak and Kali, 2001). In this literature, groups are formed in order to access the group lending contract with joint liability offered by lenders. In our model, instead, MLGSs are created with the purpose of pooling personal wealth and accessing the individual separating contract with collateral. Therefore, unlike in group formation models we admit that potential entrepreneurs possess a certain amount of collateralisable wealth. Moreover, in our model the assortative matching property of the group is triggered by the different incentives to constitute an MLGS of safe and risky borrowers and not by the peer selection effect. In this respect, our analysis is similar in spirit to Armendariz de Aghion and Gollier (2000) and Laffont and N'Guessan (2000) that consider the case of potential entrepreneurs who do not know each other's type.

The rest of the paper is organized as follows. In Section 2 and 3, we present the basic model and derive the optimal individual loan contracts, respectively. The incentives to form an MLGS and the condition under which the assortative matching property holds are described in Section 4. In Section 5, we discuss comparitive static results and testable implications, and in Section 6 we conclude. 


\section{The model set-up}

The wealth-pooling role of MLGSs can be properly illustrated by building on the influential models of costly collateral by Bester (1985) and Besanko and Thakor (1987)2. Consider a continuum of risk-neutral potential entrepreneurs of measure 1, each endowed with the technology to start up a one-period investment project and an end-ofperiod collateralisable wealth $W$. Starting up the project requires a beginning-of-period monetary investment $I$, such that entrepreneurs have to borrow from a bank $I$ units of money.

Project returns follow a two-point distribution. A fraction $\theta$ of potential entrepreneurs is 'safe', endowed with projects that yield a return $Y_{s}$ with probability $p_{s}$ and zero with probability $\left(1-p_{s}\right)$. A fraction $(1-\theta)$ is 'risky', endowed with projects yielding $Y_{r}$ with probability $p_{r}<p_{s}$ and zero otherwise. All projects are positive net present value, but the expected return on safe borrowers is no lower than that on risky borrowers, $p_{s} Y_{s} \geq p_{r} Y_{r}>I$.

In addition to returns $Y$, borrowers obtain a private (either monetary or nonmonetary) benefit $B$ from being an entrepreneur, which is assumed to be non-observable and therefore non-contractible. The private benefit $B$ can be understood, for example, in terms of social status and self-esteem of being an entrepreneur, elements that may represent an important motivation to start up entrepreneurial projects, especially in low-employment regions where outside options are rather meagres. Also, it embodies rents from social (political) connections and all the elements of value that can accrue

\footnotetext{
${ }^{2}$ Freixas and Rochet (1997) provide a simplified textbook version of this type of models.
} 
to the entrepreneur by virtue of its control on enterprises's resources, like tax evasion or other forms of fund diversion. The assumption that the bank cannot observe the benefit $B$ is crucial to our results, as otherwise the bank would also extract such a surplus. In this case, the utility for borrowers from lending would be zero, like under credit rationing, and they would have no incentive to pool their wealth in order to form an MLGS ${ }^{3}$. To simplify the analysis, we further assume that the bank has myopic expectations over the borrowers' private benefit $B$, believed to be zero ${ }^{4}$.

Risk-neutral banks cannot distinguish safe from risky entrepreneurs but know their proportion. Each bank collects deposits elastically at a zero interest rate and lends in a monopoly regime ${ }^{5}$ with standard loan contracts $L_{j}=\left\{R_{j}, C_{j}\right\}$, where $R_{j}$ denotes the gross repayment and $C_{j} \in[0, W]$ the collateral requirement, with $j=r, s$. When a borrower fails to honour the contract, banks can seize returns plus pledged collateral. Due to inefficiency in contract enforcement, we assume that the bank can recover only a fraction $\beta$ of the collateral face value.

\section{Debt contracts under individual lending}

\subsection{Separating contracts}

Banks might sort safe and risky borrowers by offering two contracts, $L_{s}=\left\{R_{s}, C_{s}\right\}$ and $L_{r}=\left\{R_{r}, C_{r}\right\}$ such that the former is selected by the safe entrepreneur and the

\footnotetext{
${ }^{3}$ See equations (2) and (6) below.

${ }^{4}$ Diversely, we could assume that $B$ distributes randomly across the population and banks only know its density function. This, however, would complicate the model considerably without adding further intuition to the analysis

${ }^{5}$ The monopoly assumption seems to be a good approximation for credit markets populated by small, wealth-constrained borrowers.
} 
latter by the risky entrepreneur, and on both contracts borrowers can gain non-negative profits. Formally, the bank's maximisation program is given by:

$$
\begin{aligned}
& \max _{R_{s}, R_{r}, C_{s}, C_{r}} v_{b}=\theta\left[p_{s} R_{s}+\left(1-p_{s}\right) \beta C_{s}\right]+(1-\theta)\left[p_{r} R_{r}+\left(1-p_{r}\right) \beta C_{r}\right] \\
& \text { s.t. } \quad p_{s}\left(Y_{s}-R_{s}\right)-\left(1-p_{s}\right) C_{s} \geq 0 \\
& p_{r}\left(Y_{r}-R_{r}\right)-\left(1-p_{r}\right) C_{r} \geq 0 \\
& p_{s}\left(Y_{s}-R_{s}\right)-\left(1-p_{s}\right) C_{s} \geq p_{s}\left(Y_{s}-R_{r}\right)-\left(1-p_{s}\right) C_{r} \quad\left(I C_{s}\right) \\
& p_{r}\left(Y_{r}-R_{r}\right)-\left(1-p_{r}\right) C_{r} \geq p_{r}\left(Y_{r}-R_{s}\right)-\left(1-p_{r}\right) C_{s} \quad\left(I C_{s}\right) .
\end{aligned}
$$

Since collateral is costly for banks, borrowers are required to pledge collateral to the minimum extent necessary to make the separation feasible. Now consider the pair of contracts $L_{s}^{S}$ and $L_{r}^{S}$, such that $\left(P C_{s}\right),\left(P C_{r}\right)$ and $\left(I C_{r}\right)$ are binding:

$$
\begin{aligned}
L_{s}^{S} & =\left\{R_{s}^{S}=\frac{p_{s} Y_{s}-p_{r} Y_{r}+p_{s} p_{r}\left(Y_{r}-Y_{s}\right)}{p_{s}-p_{r}} ; C_{s}^{S}=\frac{p_{s} p_{r}\left(Y_{r}-Y_{s}\right)}{p_{s}-p_{r}}\right\} \\
L_{r}^{S} & =\left\{R_{r}^{S}=Y_{r} ; C_{r}^{S}=0\right\}
\end{aligned}
$$

From (1), the repayment required by the bank with contract $L_{s}^{S}$ is clearly feasible, that is $R_{s}^{S}<Y_{s}$, and $\left(I C_{s}\right)$ is also met. Moreover:

Lemma 1 If $\theta<\widehat{\theta}=\frac{\left(p_{s}-p_{r}\right)}{\left(p_{s}-p_{r}\right)+p_{s}\left(1-p_{s}\right)(1-\beta)}$, the pair of contracts $L_{s}^{S}$ and $L_{r}^{S}$ in (1) is the optimal separating equilibrium.

Proof. Let $v_{b}^{S}$ be the bank's expected profits from offering contracts $L_{s}^{S}$ and $L_{r}^{S}$. 
The bank might reduce by $\Delta R_{r}^{S}$ the interest charged to risky borrowers with a loss in expected profits equal to $(1-\theta) p_{r} \Delta R_{r}^{S}$. In this way, the bank softens the incentive constraint for risky borrowers and could offer a new self-selecting safe-contract $L_{s}^{S \prime}$ with lower collateral and higher interest rate. Substituting $R_{s}^{S}$ obtained from $\left(P C_{s}\right)$ into $\left(I C_{r}\right)$, we easily find that, with respect to the contract $L_{s}^{S}$, the new contract $L_{s}^{S \prime}$

provides an increase in interest rate equal to $p_{r}\left(1-p_{s}\right)\left(p_{s}-p_{r}\right)^{-1} \Delta R_{r}^{S}$ and a reduction in the collateral to $p_{s} p_{r}\left(p_{s}-p_{r}\right)^{-1} \Delta R_{r}^{S}$. For the bank, these changes in the contract entail expected gains equal to $\theta p_{s} p_{r}\left(1-p_{s}\right)(1-\beta)\left(p_{s}-p_{r}\right)^{-1} \Delta R_{r}^{S}$. If $\theta<\widehat{\theta}$, the expected loss on risky contracts $L_{r}^{S \prime}$ is always higher than the expected gain on safe contracts $L_{s}^{S \prime}$, such that $v_{s}^{S \prime}<v_{s}^{S}$ for any $\Delta R_{r}^{S}<0$, hence proving Lemma 1.

The economic intuition of Lemma 1 is straightforward. When the share of safe borrowers is not very large, the bank maximises its whole profit by maximising revenues on loans to $r$-type and forgoing part of the profit realizable with a reduction in the collateral requirement on $s$-type loans as in contract $L_{s}^{S \prime}$. Since in equilibrium banks extract all the rent from both types of projects, borrowers' net utility is simply the private benefit $B$ :

$$
U_{s}\left(L_{s}^{S}\right)=U_{r}\left(L_{r}^{S}\right)=B
$$

\subsection{Credit-rationing equilibrium}

Assume that borrowers are wealth-constrained and cannot apply for the separating safecontract $L_{s}^{S}$, i.e., assume that $W<C_{s}^{S}$. In this case the bank maximizes its expected profit by offering either a pooling or a separating contract. Following the same logic as 
Lemma 1 , if $\theta<\widehat{\theta}$ the optimal separating contract requires safe borrowers to pledge all their wealth as collateral:

$$
\begin{aligned}
& \widetilde{L}_{s}^{S}=\left\{R_{s}^{S}=Y_{s}-\frac{1-p_{s}}{p_{s}} W ; C_{s}^{S}=W\right\} \\
& \widetilde{L}_{r}^{S}=\left\{R_{r}^{S}=Y_{s}+\frac{p_{s}-p_{r}}{p_{s} p_{r}} W ; C_{r}^{S}=0\right\}
\end{aligned}
$$

The bank's expected profit is:

$$
\begin{aligned}
v_{b}\left(\widetilde{L}_{s}^{S} ; \widetilde{L}_{r}^{S}\right)= & \theta p_{s}\left(Y_{s}-\frac{1-p_{s}}{p_{s}} W\right)+\theta\left(1-p_{s}\right) \beta W+ \\
& +(1-\theta) p_{r}\left(Y_{s}+\frac{p_{s}-p_{r}}{p_{s} p_{r}} W\right)-I
\end{aligned}
$$

With regard to the pooling contract, we have three possible candidates. First, the bank could ask all borrowers to pledge their wealth as collateral and charge the interest rate that makes monetary profits of safe borrowers equal to zero, such that all potential entrepreneurs may ask for credit: $L_{1}^{P}=\left\{R_{1}^{P}=Y_{s}-\frac{1-p_{s}}{p_{s}} W ; C_{1}^{P}=W\right\}$. However, it can be shown that this contract is not profit-maximising because $v_{b}\left(L_{1}^{P}\right)<v_{b}\left(\widetilde{L}_{s}^{S} ; \widetilde{L}_{r}^{S}\right)$ for any $\beta<1$.

Second, the bank could offer a contract with zero collateral and the interest rate that satisfies $(P C s)$ as equality: $L_{2}^{P}=\left\{R_{2}^{P}=Y_{s} ; C_{2}^{P}=0\right\}$. Once again, this contract is not profit-maximising since, when $\theta<\widehat{\theta}, v_{b}\left(L_{2}^{P}\right)<v_{b}\left(\widetilde{L}_{s}^{S} ; \widetilde{L}_{r}^{S}\right)$.

Finally, the bank could offer a contract asking for zero collateral and an interest rate equal to the positive return on the risky project: $L^{P}=\left\{R^{P}=Y_{r} ; C^{P}=0\right\}=L_{r}^{S}$. In 
this case, safe borrowers are excluded from the credit market and the bank's expected profit is:

$$
v_{b}\left(L^{P}\right)=(1-\theta)\left(p_{r} Y_{r}-I\right)
$$

Lemma 2 If $\theta<\min \left[\widehat{\theta}, \frac{p_{r}\left(Y_{r}-Y_{s}\right)}{p_{r}\left(Y_{r}-Y_{r}\right)+p_{s} Y_{s}-1}\right]$, a wealth $\bar{W}>0$ exists such that $v_{b}\left(L^{P}\right)<$ $v_{b}\left(\widetilde{L}_{s}^{S} ; \widetilde{L}_{r}^{S}\right)$ holds for any $W \in(0, \bar{W})$, and a credit-rationing equilibrium prevails.

Proof. By comparing equations (4) and (5), it is easy to show that $v_{b}\left(L^{P}\right)<$ $v_{b}\left(\widetilde{L}_{s}^{S} ; \widetilde{L}_{r}^{S}\right)$ if $W<\bar{W}=\frac{p_{s}\left[(1-\theta) p_{r}\left(Y_{r}-Y_{s}\right)-\theta\left(p_{s} Y_{s}-I\right)\right]}{(1-\theta)\left(p_{s}-p_{r}\right)-p_{s}\left(1-p_{s}\right)(1-\beta)}$. If $\theta<\widehat{\theta}$, the denominator of such an expression is certainly positive, while its numerator is positive only if $\theta<$ $\frac{p_{r}\left(Y_{r}-Y_{s}\right)}{p_{r}\left(Y_{s}-Y_{r}\right)+p_{s} Y_{s}-I}$.

Hence, if the available wealth is sufficiently lower than the collateral required on the separating contract $L_{s}^{S}$, the bank maximises its expected profit by offering a pooling contract that ration safe borrowers by raising the interest rate to $Y_{r}$. In a creditrationing equilibrium, risky entrepreneurs obtain the private benefits $B$, while safe entrepreneurs are excluded from the credit market and gain zero utility:

$$
U_{s}\left(L^{P}\right)=0 ; \quad U_{r}\left(L^{P}\right)=B
$$

\section{Borrowing through mutual loan-guarantee societies}

Assume that investors can participate in an MLGS by contributing with a part $w \leq W$ of their wealth to a collective fund. This fund will be employed to pledge the collateral required by the bank in favour of MLGS members who thus become indirectly jointly 
liable for each other's loan repayment.

Also, assume that the MLGS does not have any informational advantages over banks with regard to their members. Each member is entitled to apply for the loan guarantee of the MLGS. If, like in the case of individual borrowing with separating contracts (1), we exclude the possibility of any MLGS member making side payments in exchange for the right to use the wealth of another, the collateral pledged to the bank has to be the same for all members, whether safe or risky. In this case, MLGSs can display alternatively assortative and non-assortative matching of investors, being composed by either safe entrepreneurs only, risky entrepreneurs only or by both types of entrepreneurs.

Since banks do not observe the benefit $B$ entrepreneurs can gain from acceding to the credit market, they cannot anticipate what type of entrepreneurs find it profitable to form and participate in an MLGS (see below, Proposition 1), and hence cannot design loan contracts differently than under individual lending. Moreover, absent any peer (selection or monitoring) effect, lending to a member of an MLGS is for the bank equivalent to lending to an individual borrower. Therefore, we have:

Lemma 3 Let $\theta<\widehat{\theta}$ and $W<\bar{W}$, and let banks be monopolist against MLGS members. Then the optimal loan contracts offered by banks to MLGSs is: $L^{M}=L_{s}^{S}$.

Proof. The proof can run intuitively. Since $W<\bar{W}$, the optimal contract offered by banks to individual borrowers is the pooling contract $L^{P}$, which is equivalent to the risky contract under separating equilibrium (see Lemma 2). Therefore, the value of $B$ being unobservable and given $\theta<\widehat{\theta}$, from Lemma 1 the profit-maximising loan contract 
offered by banks to MLGS members is the safe-separating contract, $L^{M}=L_{s}^{S}$.

Since $W<C_{s}^{S}$, guarantees by the MLGS can be granted only to a share $q=w / C_{s}^{S}$ of the members. Assume that those members who are refused the loan guarantee cannot apply to the bank for individual lending in the same period. Let $U_{j z}\left(L^{M}\right)$ be the net utility for a $j$-type investor of participating in an MLGS with $z$-type members, with $j, z=s, r$. Given the separating contracts (1) and since $q<1$, clearly $U_{j z}\left(L^{M}\right)<$ $U_{j}\left(L_{j}^{S}\right)$ for any $j$ and $z$. Therefore, in the absence of credit rationing, it would not be worthwhile for either $s$ - or $r$-type borrowers to form an MLGS.

By contrast, under the pooling contract, safe borrowers are credit-rationed, their net utility is zero and they have incentives to establish an MLGS and pool their wealth for applying for the MLGS contract. In turn, r-type may find it worth joining the MLGS with safe entrepreneurs. This is because under the MLGS contract they can borrow at conditions that are equivalent to those required with the $r$-type separating individual contract (recall that for risky borrowers the incentive constraint is binding and $L_{r}^{S} \sim L_{s}^{S}$ ), but they can still take advantage of the joint liability and reduce the probability of losing their wealth.

Proposition 1 Suppose that investors cannot observe each other's type, that banks cannot observe the private benefit of becoming entrepreneur $B$ and that in the credit market a rationing equilibrium prevails. Then:

Case I. When the private benefit of being an entrepreneur is sufficiently high, i.e., when $B \geq \widetilde{B}=\theta\left(p_{s}-p_{r}\right) W C_{s}^{S}\left(C_{s}^{S}-W\right)^{-1}$, risky investors will prefer to borrow individually through the separating contract, whereas safe investors will gain from forming an 
$M L G S$.

Case II. When $B$ is lower than $\widetilde{B}$, risky investors have an incentive to join an $M L G S$ in which safe investors participate. In turn, safe investors have an incentive to join an $M L G S$ in which risky investors participate only if $B \geq \widehat{B}=(1-\theta)\left(p_{s}-p_{r}\right) C_{s}^{S}$. In this case, a necessary condition for a non-assortative $M L G S$ to exist is $(1-\theta)<W / C_{s}^{S}$.

Proof. Case I. In order for assortative matching to prevail either $U_{r r}\left(L^{M}\right)>U_{r}\left(L^{P}\right)$ and $U_{s r}\left(L^{M}\right) \leq U_{s}\left(L^{P}\right)$ or $U_{s s}\left(L^{M}\right)>U_{s}\left(L^{P}\right)$ and $U_{r s}\left(L^{M}\right) \leq U_{r}\left(L^{P}\right)$ have to hold, where:

$$
\left\{\begin{array}{l}
U_{r r}\left(L^{M}\right)=\frac{w}{C_{s}^{S}}\left[p_{r}\left(Y_{r}-R_{s}^{S}\right)+B\right]-\left(1-p_{r}\right) w \\
U_{s s}\left(L^{M}\right)=\frac{w}{C_{s}^{S}}\left[p_{s}\left(Y_{s}-R_{s}^{S}\right)+B\right]-\left(1-p_{s}\right) w \\
U_{r s}\left(L^{M}\right)=\frac{w}{C_{s}^{S}}\left[p_{r}\left(Y_{r}-R_{s}^{S}\right)+B\right]-\left(1-p_{\theta}\right) w \\
U_{s r}\left(L^{M}\right)=\frac{w}{C_{s}^{S}}\left[p_{s}\left(Y_{s}-R_{s}^{S}\right)+B\right]-\left(1-p_{\theta}\right) w
\end{array}\right.
$$

where $p_{\theta}=\lambda \theta p_{s}+\gamma(1-\theta) p_{r}$, and where $\lambda$ and $\gamma$ are the shares of safe and risky entrepreneurs that join the MLGS. Recalling that the pair $R_{s}^{S}$ and $C_{s}^{S}$ are such that the participation constraints for $s$ - and $r$-investors as well as the incentive constraint for the $r$-type are all binding, the above expressions for the borrowers' utility can be simplified and rewritten as:

$$
U_{r r}\left(L^{M}\right)=U_{s s}\left(L^{M}\right)=\frac{w}{C_{s}^{S}} B ; \quad\left\{\begin{array}{l}
U_{r s}\left(L^{M}\right)=\frac{w}{C_{s}^{S}} B+w\left(p_{\theta}-p_{r}\right) \\
U_{s r}\left(L^{M}\right)=\frac{w}{C_{s}^{S}} B+w\left(p_{\theta}-p_{s}\right)
\end{array}\right.
$$

Since the net utility of forming an MLGS, $U_{j z}\left(L^{M}\right)-U_{j}\left(L^{P}\right)$, is not decreasing with 
$w$ for any $j$ and $z$, investors find it optimal to participate in the MLGS's guarantee fund with all their wealth and maximise the probability of gaining access to the loan guarantee: $w=W$. From (7) and (6) clearly $U_{r r}\left(L^{M}\right)<U_{r}\left(L^{P}\right)$ always holds and the only possible assortative equilibrium is that with safe investors in the MLGS and risky investors borrowing individually out of the MLGS. Again, from (7) and (6), we have $U_{s s}\left(L^{M}\right)>U_{s}\left(L^{P}\right)$. Moreover, since $U_{r s}$ and $U_{s r}$ are strictly increasing with $\gamma$ and $\lambda$ respectively, if we rule out problems of coordination, the utility of risky (safe) entrepreneurs is maximised when all of them participate in the MLGS, regardless of the number of safe (risky) entrepreneurs already in the MLGS. Therefore, we can substitute for $\lambda=\gamma=1$ into $p_{\theta}$ and easily verify that $U_{r s}\left(L^{M}\right) \leq U_{r}\left(L^{P}\right)$ only if $B \geq \widetilde{B}$.

Case II. When $B<\widetilde{B}, U_{r s}\left(L^{M}\right)>U_{r}\left(L^{P}\right)$ and risky investors find it profitable to join an MLGS with safe investors. The latter, however, gain from participating in an MLGS with risky investors only if $U_{s r}\left(L^{M}\right)>U_{s}\left(L^{P}\right)=0$, that is, recalling that $\lambda=\gamma=1$, only if $B \geq \widehat{B}$. Therefore, a non-assortative equilibrium can exist only if $\widehat{B}<\widetilde{B}$, that is if $(1-\theta)<W / C_{s}^{S}$.

The economic intuition of Proposition 1 is the following. In a rationing equilibrium, safe entrepreneurs cannot individually apply for a loan and lose the private benefit $B$. By establishing an MLGS they can obtain credit and the benefit $B$ with probability $q=W / C_{s}^{S}$. For risky investors, instead, joining the MLGS means accepting a positive probability of being rationed and incurring the loss of the benefit of becoming an entrepreneur but gaining the opportunity to share the risk of losing their wealth with the safe investors. When $B$ is high, the expected loss of rationing outweighs the benefit of 
risk sharing and induces $r$-investors to borrow individually. In this case, an assortative equilibrium prevails with MLGSs formed by only $s$-type associates. When $B<\widetilde{B}$, risky investors find it profitable to join an MLGS with safe investors. However, in order for a non-assortative MLGS to be formed, safe investors too must gain from participating in an MLGS with risky partners. This is the case if the incentive of having a positive probability of obtaining the private benefit of entrepreneurship is strong enough to outweigh the negative effects of sharing the credit risk with risky partners $B$, i.e., if $B \geq \widehat{B}$. Obviously, the concurrent participation of risky and safe investors in an MLGS is possible only if the threshold level of $B$ which makes it profitable for safe investors to participate in a non-assortative MLGS, is no higher than the threshold level of $B$ which makes the participation of risky investors profitable (i.e., $\widetilde{B} \geq \widehat{B}$ ). This condition is satisfied if the probability of obtaining the guarantee of the MLGS, $q=W / C_{s}^{S}$, exceeds the share of risky partners in the MLGS, $(1-\theta)$.

When $B$ is less than $\widehat{B}$ (or less than $\widetilde{B}$, if $\widetilde{B}<\widehat{B}$ ), $r$-type investors have an incentive to join an MLGS in which safe investors participate, while $s$-type have no incentive to join an MLGS with risky borrowers and thus the MLGS cannot be formed.

\section{Comparative statics and empirical implications}

Our theory suggests a number of empirical implications concerning the structure and performance of MLGSs. First, loans that take advantage of the MLSG's guarantee exhibit, on average, a lower rate of default than individual loans.

Proposition 2 Suppose that in the credit market a rationing equilibrium prevails and 
an MLGS is established. The ratio of default on MLGS loans to default on individual loans is $d_{s s}^{M}=\left(1-p_{s}\right) /\left(1-p_{r}\right)$ in the case of assortative matching and $d_{r s}^{M}=$ $\left(1-p_{\theta}\right) /\left(1-p_{r}\right)$ in the case of non-assortative matching with $d_{s s}^{M}<d_{r s}^{M}<1$.

It is worth noting that the lower riskiness of firms belonging to an MLGS is simply due to the fact that the guarantee society is joined by safe investors who would otherwise be excluded from the credit market, and not to the better screening and monitoring capacities of peers.

Other implications can be figured out from the following comparative static results on the threshold values $\bar{W}$ and $\widetilde{B}$ for the existence of assortative and non-assortative MLGSs.

Lemma $4 \frac{\partial \bar{W}}{\partial \theta}<0 ; \frac{\partial \bar{W}}{\partial \beta}<0 ; \frac{\partial \widetilde{B}}{\partial \theta}>0 ; \frac{\partial \widetilde{B}}{\partial W}>0$.

Signs of partial derivatives reported in Lemma 4 have straight interpretations. First, the greater the share of safe entrepreneurs in the economy and the less costly it is for banks to recoup pledged collateral, the less likely it is that a credit-rationing equilibrium prevails and MLGSs form. Second, where safe entrepreneurs are actually rationed, an increase in the share of safe entrepreneurs and in the collateralisable wealth (together with a reduction in collateral requirements), all make assortative MLGSs less likely.

Now, if we reasonably assume that in backward regions $\theta, \beta$ and $W$ are typically lower than in developed economies, whereas and $B$ are higher, we can state the following testable proposition.

Proposition 3 In backward regions: (1) the number of MLGSs is relatively (with respect to the number of firms in the economy) higher than in developed regions; (2) 
MLGSs usually have fewer associates than in developed economies; (3) the repayment rate of loans guaranteed by MLGSs is relatively (with respect to the average riskiness of local borrowers) higher than in developed regions.

In the light of Lemma 4, the economic intuition behind Proposition 3 is clear. First of all, in backward regions, where the average quality of entrepreneurs is lower, courts are less efficient and civil trials to recover collateral are longer and costlier, the inefficient credit rationing of safe borrowers is more likely and therefore the incentive to form MLGSs is stronger and their number is greater than in well-developed regions. Second, since in backward regions the assortative matching equilibrium is more likely to prevail with only safe investors having an interest to pool their wealth in a mutual society, in these regions MLGSs usually have fewer associates and their loan-repayment rate is relatively much higher than that of other non-guaranteed local firms.

Propositions 2 and 3 are broadly consistent with empirical evidence for Italy, where mutual loan guarantee schemes are widely in use and the differences in economic development between southern (the so-called Mezzogiorno) and centre-northern regions are very pronounced. For example, according to data reported in Columba et al. (2006), out of 1,073 MLGSs listed in the register of "Ufficio Italiano Cambi" (UIC - Italian Office of Exchanges) in 2004, 44 percent are located in southern, less developed regions, whereas the number of firms with fewer than 20 employees operating in the south amounts to only 27 of the national total. As a consequence, the number of MLGSs per 10,000 firms is twice the number in centre-northern regions. If we focus on craft firms, at the end of 2007, 47.4 percent of MLGSs belonging to the Italian Federation of Craft Guarantee 
Societies (Fedart Fidi) were located in the South, while in these regions the number of firms listed in the official register of craft enterprises is only 25 percent of the total ${ }^{6}$.

Secondly, the average number of associated firms per MLGS in the South of Italy is about one fourth of that prevailing in central and northern regions (Columba et al., 2008; Fedart Fidi, 2009). Similarly, the MLGSs' own funds and the outstanding guarantees in portfolio are far lower in southern MLGSs than in those located elsewhere.

Third, small firms guaranteed by an MLGS have, on average, a rate of default that is about half that experienced by non-guaranteed small firms. However, even more interestingly, if compared with the average default rate on loans granted in the region, the rate of repayment is higher for southern MLGs than for centre-northern MLGSs. For example, according to Bank of Italy figures, the ratio of bad to total loans for craft enteprises is 4.8 percent in northern regions, 6.9 in central regions and 12.2 in southern regions. For craft firms belonging to northern, central and southern MLGSs the percentage of bad loans is 4, 2.7 and 4.2, respectively. Besides this descriptive evidence, the higher repayment rate of loans guaranteed by southern MLGSs is also proved by the multivariate analysis presented in Columba et al. (2008), who analyse a large sample of 385,000 firms with less than 20 employees. Specifically, they estimate a probit model with fixed effect by sector of activity where the dependent variables analysed are, alternatively, the probability that a firm is classified as non-performing by at least one lending bank and the probability that it is classified as non-performing between June 2004 and June 2005. They find that for firms guaranteed by an MLGS the probability of default is 5 percent lower than for other firms, but for southern firms

\footnotetext{
${ }^{6}$ See Fedart Fidi (2009)
} 
guaranteed by MLGSs the decrease in the default probability is as high as 11 percent.

\section{Conclusion}

In many countries, an increasing number of small and micro enterprises are affiliated to MLGSs and gain access to bank loans thanks to the collective guarantee granted by such institutions. In this paper we advance a theory to rationalise the existence of MLGSs focused on their distinctive function of pledging collateral for loans granted to their members. The basic intuition is that the foundation for MLGSs lies in the inefficiencies created by adverse selection, when borrowers do not have enough collateralisable wealth to satisfy collateral requirements and induce self-selecting contracts. In this setting, we view MLGSs as a wealth-pooling mechanism that allows otherwise inefficiently rationed borrowers to obtain credit. Despite abstracting from any peer selection and peer monitoring mechanisms, we find that MLGSs can be characterized by assortative matching in which only safe borrowers have incentives to join the mutual society. 


\section{References}

AECM (2005). The 2003 activity report of AECM members. Technical report, AECM - Association Européenne du Cautionnement Mutuel. Available at http://www. aecm.be.

Armendariz de Aghion, B. and C. Gollier (2000). Peer group formation in an adverse selection model. Economic Journal 110(July), 623-43.

Beck, T., L. F. Klapper, and J. C. Mendoza (2008). The typology of partial credit guarantee funds around the world. World Bank, Policy Research Working Paper No. 4771.

Besanko, D. and A. Thakor (1987). Collateral and rationing: Sorting equilibria in monopolistic and competitive markets. International Economic Review 28(3), 67189.

Bester, H. (1985). Screening vs rationing in credit markets with imperfect information. American Economic Review 75(4), 850-55.

Columba, F., L. Gambacorta, and P. E. Mistrulli (2006). L'attività dei consorzi di garanzia collettiva dei fidi in Italia. Bancaria 62(7-8), 84-96.

Columba, F., L. Gambacorta, and P. E. Mistrulli (2008). Firms as monitor of other firms: Mutual guarantee institutions and SME finance. Available at http://mpra.ub.uni-muenchen.de/14032.

European Commission (2005). Guarantees and mutual guarantees. Best report: Report 
to the Commission by an independent expert group. Technical report, European Commission. Available at http://ec. europa.eu.

Fedart Fidi (2009). Il sistema dei confidi artigiani aderenti a fedart fidi. Technical report, Fedart Fidi. Available at http://www.fedartfidi.it.

Freixas, X. and J.-C. Rochet (1997). Microeconomics of Banking. Cambridge, Mass.: The MIT Press.

Ghatak, M. (2000). Screening by the company you keep: Joint liability lending and the peer selection effect. Economic Journal 110(July), 601-31.

Ghatak, M. and R. Kali (2001). Financially interlinked business groups. Journal of Economics and Management Strategy 10(4), 591-619.

Gonzàles, P., H. Sànchez, J. N. Sobrino, and M. J. Vàsquez de Francisco (2006). The european framework of guarantee systems/schemes: Main characteristics and concepts. Fundacion ETEA Working Paper.

Honohan, P. (2008). Partial credit guarantee: Principles and practice. IIIS Discussion Paper No. 244.

Laffont, J.-J. and T. N'Guessan (2000). Group lending with adverse selection. European Economic Review 44(4-6), 773-84. 